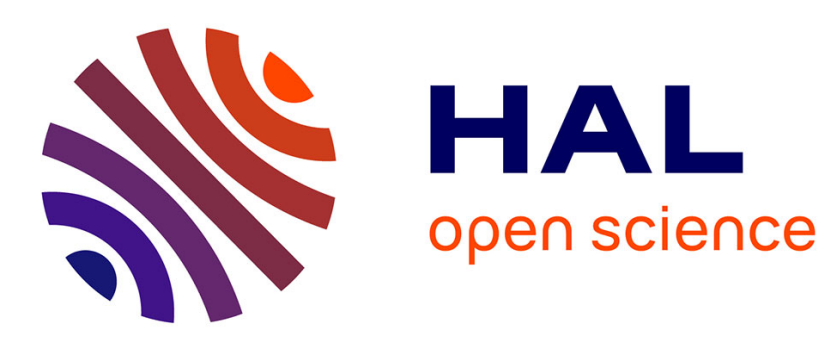

\title{
Influence of the pulse number and fluence of a nanosecond laser on the ablation rate of metals, semiconductors and dielectrics
}

I. Vladoiu, M. Stafe, C. Negutu, I.M. Popescu

\section{- To cite this version:}

I. Vladoiu, M. Stafe, C. Negutu, I.M. Popescu. Influence of the pulse number and fluence of a nanosecond laser on the ablation rate of metals, semiconductors and dielectrics. European Physical Journal: Applied Physics, 2009, 47 (3), pp.1-6. 10.1051/epjap/2009100 . hal-00490917

\section{HAL Id: hal-00490917 https://hal.science/hal-00490917}

Submitted on 10 Jun 2010

HAL is a multi-disciplinary open access archive for the deposit and dissemination of scientific research documents, whether they are published or not. The documents may come from teaching and research institutions in France or abroad, or from public or private research centers.
L'archive ouverte pluridisciplinaire HAL, est destinée au dépôt et à la diffusion de documents scientifiques de niveau recherche, publiés ou non, émanant des établissements d'enseignement et de recherche français ou étrangers, des laboratoires publics ou privés. 


\title{
Influence of the pulse number and fluence of a nanosecond laser on the ablation rate of metals, semiconductors and dielectrics
}

\author{
I. VLADOIU, M. STAFE, C. NEGUTU, I. M. POPESCU \\ Physics Department, Faculty of Applied Sciences, University "Politehnica” of Bucharest, Splaiul Independentei \\ 313, 060042 Bucharest, Romania, Tel: + 4021. 402.91.02; Fax: + 4021. 402.91.20 \\ e-mail: vladoiu@physics.pub.ro, $\underline{\text { stafe @ physics.pub.ro }}$
}

\begin{abstract}
We investigated the pulsed laser ablation of metallic ( $\mathrm{Al}$ ), semiconductor ( $\mathrm{Si}$ ), and wide bandgap dielectric $\left(\mathrm{LiNbO}_{3}\right)$ targets in air at normal atmospheric conditions by using $4.5 \mathrm{~ns}$ pulses at $532 \mathrm{~nm}$ wavelength. We determined the dependence of the ablation rate on the pulse number and laser fluence. The number of consecutive laser pulses hitting the target on the same area was between 5 and 40, and the laser fluence was varied in the range of 10-250 $\mathrm{J} / \mathrm{cm}^{2}$ by changing the irradiated area at the target surface. We find that the ablation rate of the three targets is approximately constant when the pulse number is smaller than 15 . Further increase of the pulse number leads to a decrease of the ablation rate, the fastest decrease of the ablation rate with pulse number being observed for the dielectric target. The dependence of the ablation rate on the laser fluence indicates two different regimes. In the first regime, which is for values of the fluence smaller than the threshold value $\left(\sim 70 \mathrm{~J} / \mathrm{cm}^{2}\right.$ for $\mathrm{Al}, \sim 90 \mathrm{~J} / \mathrm{cm}^{2}$ for $\mathrm{Si}$, and $\sim 180 \mathrm{~J} / \mathrm{cm}^{2}$ for $\mathrm{LiNbO}_{3}$ ), the ablation rate increases approximately logarithmically with the fluence. In the second regime, characterized by values of the fluence greater than the threshold value, there is a steep increase of the ablation rate. This sudden jump of the ablation rate at the threshold fluence is due to the transition from normal vaporisation to phase explosion, and to the changes in the dimensionality of the plasma-plume hydrodynamics from one-dimensional to three-dimensional.
\end{abstract}

Keywords: ablation rate, threshold fluence

PACS: 42.62.-b, 61.82.Bg, 61.82.Fk, 61.82.Ms, 81.20.-n,

\section{Introduction}

The efficiency of the pulsed laser ablation (PLA) is described by the ablation rate which gives the maximum thickness of the layer ablated during a laser pulse. The ablation rate is a key parameter for the continuously growing fields of applications of PLA, such as optoelectronics, micromechanics, pulsed laser deposition, and laser induced plasma spectrometry [1-10].

The characteristics of the laser beam, ablated material, and ambient atmosphere strongly influences the ablation rate [1-6,8,11-23]. Previous experiments on PLA in multipulse regime indicated that the ablation rate of metals decreases exponentially with pulse number [1,17]. This was attributed mainly to the superposition of two effects: less efficient transport of the ablated material with increasing crater depth, and enhanced attenuation of the incident pulses in the laser produced plasma plume $[1,18]$. In the case of semiconductors and dielectrics it was demonstrated that the ablation rate increases logarithmically with the laser fluence $[1,12]$. Our previous experiments on PLA indicated this logarithmic behaviour in the case of metals and, additionally, allowed us to identify a threshold fluence above which there is a sudden jump of the ablation rate [11]. The jump of the ablation rate at the threshold fluence was related to the superposition of two effects: the phase explosion, which refers to the transition from a superheated liquid to a mix of vapours and droplets that occurs when 
material surface pass the thermodynamic critical temperature, and the change of the dimensionality of the plasma plume hydrodynamics from one-dimensional to threedimensional [11,12,14,24, 29].

Here, we provide further insight into PLA by investigating the efficiency of the ablation of three materials with very different thermal and optical properties (metal- $\mathrm{Al}$, semiconductor- $\mathrm{Si}$, and wide bandgap dielectric- $\mathrm{LiNbO}_{3}$ ) in open air. We determine the dependence of the ablation rate of the three materials on the pulse number and the laser fluence at $532 \mathrm{~nm}$ wavelength in two steps. First, by fixing the targets in the focal plane of the focusing lens, we analyse the dependence of the ablation rate on the number of consecutive pulses that hit the target in the same area. The analysis indicates the maximum number of pulses for which the ablation rate is approximately constant. Second, by setting a small number of pulses and varying the laser fluence by changing the diameter of the irradiated area on the target surface, we demonstrate two different domains in the dependence of the ablation rate on the fluence. The sudden jump of the ablation rate at the limit of the two domains appears for a given laser fluence (referred to as the threshold fluence), which is demonstrated to depend on the thermal and optical properties of the material.

\section{Experiment}

The laser system employed here consists of a Q-switched Nd:YAG laser that works in TEM00 mode, having $1.4 \mathrm{~cm}^{-1}$ line-width ( 170 longitudinal modes) at $532 \mathrm{~nm}$ wavelength of the second harmonic. The laser pulses with $4.5 \mathrm{~ns}$ duration and $180 \mathrm{~mJ} / \mathrm{pulse}$ energy are emitted at $10 \mathrm{~Hz}$ repetition rate.

The laser pulses are focused at normal incidence by a quartz lens $(\mathrm{f} / 10, \mathrm{f}=10 \mathrm{~cm})$ on the surface of the thick targets (thickness larger than $1 \mathrm{~mm}$ ) which are placed in the focal plane at normal atmospheric conditions, the estimated Rayleigh length being $\sim 200 \mu \mathrm{m}$. A number of laser pulses, which varies between 5 and 40, hit the target producing craters that are characterised by their depth and diameter. The diameter of the craters is varied in the range 0.03 to $0.16 \mathrm{~cm}$ by moving the targets away from the focal plane with a translation step of $2 \mathrm{~mm}$ by using a micro-mechanical stage. We move the targets toward lens system in order to avoid the air breakdown that would lead to loss of the pulse energy into the ignited plasma plume.

The diameter of the craters drilled at different positions of the target approximate the diameter of the irradiated area [22, 27]. Then, the laser fluence corresponding to a given target position along its path away from the focal plane is derived by dividing the energy pulse by the irradiated area.

The depth of the craters that are drilled at different target positions is used to calculate the ablation rate by dividing the depth of the crater by the number of laser pulses that were used to drill the craters.

The depth and diameter of the craters were measured by using a Leica Microsystems Heidelberg GmbH confocal microscope. The relative errors of the craters depth and craters diameter that we measured are within $5 \%$.

\section{Results and discussion}

The dependence of the crater depth on the pulse number $(N)$ for of $\mathrm{Al}, \mathrm{Si}$ and $\mathrm{LiNbO}_{3}$ targets is presented in Figure 1. The targets are fixed in the focal plane, while the number of consecutive laser pulses hitting the target in the same area increase from 5 to 40 . Fig. 1 indicates that the depth of the crater $(h)$ increases linearly with pulse number when this number goes from zero to $\sim 15$; the slope of the dash-dotted lines that fit the experimental data 
gives the ablation rate. Consequently, during first stages of PLA in multi-pulse regime, the ablation rate is approximately constant, being $\sim 8.3 \mu \mathrm{m} /$ pulse for $\mathrm{Al}$ and $\sim 2.7 \mu \mathrm{m} /$ pulse for $\mathrm{Si}$ (at a fluence of $\sim 150 \mathrm{~J} / \mathrm{cm}^{2}$ ), and $\sim 1.7 \mu \mathrm{m} /$ pulse for $\mathrm{LiNbO}_{3}$ (at a fluence of $\sim 250 \mathrm{~J} / \mathrm{cm}^{2}$ ).

Further increase of the pulse number leads to a non-linear increment of the crater depth. The fitting curves (solid lines in Fig. 1) indicate that the ablation rate ceases to be constant: it decays with increasing pulse number. The fitting curves are described by the equation

$h=h_{1} N^{d}$,

where $h_{1}$ denotes the crater depth corresponding to one single pulse. $d$ indicates the deviation of the fitting curve from the dash-dotted straight line that fits the first 3 (for $\mathrm{LiNbO}_{3}$ ) or 4 (for $\mathrm{Al}$ and $\mathrm{Si}$ ) experimental points indicated in the graphs of Fig. 1: the closer to unit is $d$ the closer to a constant is ablation rate when increasing the pulse number. The value of the $d$ coefficient in eq. (1) is $\sim 0.94$ for $\mathrm{Al}$ and $\mathrm{Si}$, and $\sim 0.69$ for $\mathrm{LiNbO}_{3}$, indicating that the ablation rate decays much stronger with pulse number in the case of the dielectric target as compared to the metallic and semiconductor targets. The data indicate that in the case of dielectric material the ablation rate corresponding to the $40^{\text {th }}$ pulse is $\sim 50 \%$ smaller than its value for the first pulses, whereas in the case of metallic and semiconductor targets is only $\sim 15 \%$ smaller.

The decrease of the ablation rate with pulse number can be related to the superposition of two effects which are determined by the increment of the crater depth with pulse number. First, the increase of the crater depth leads to the confinement of the plasma plume within the crater. This is asserted by comparing the plasma hydrodynamic length and the crater depth: for a nanosecond pulse, the speed of the ablated species is $\sim 10^{3} \div 10^{4} \mathrm{~m} / \mathrm{s}$ [1]. Thus, during a laser pulse, the ablation products travel away from the target $\sim 20 \div 200 \mu \mathrm{m}$; this means that the hydrodynamic length is comparable with the depth of the crater after irradiation with 40 laser pulses. The plasma confinement leads to strong attenuation of the laser beam by scattering and inverse Bremsstrahlung absorption into the plasma plume and to less efficient transport of the ablated species, and enhanced recondensation of the material.

Second, the increase of the crater depth with pulse number leads to the increase of the inclination of the irradiated area relative to the original target surface. Thereby, the incidence angle of the laser beam at the irradiated area increases with pulse number, leading to the decrease of the surface transmittance and of the effective laser fluence at the walls of the crater, and consequently to the increase of energy loss by heat conduction [18]. The much smaller thermal diffusivity of the dielectric target as compared to the metallic and semiconductor targets (see table 1) leads to the much faster decrease of the ablation rate of $\mathrm{LiNbO}_{3}$ with pulse number.

By setting a small number of laser pulses for hitting the target, which imply a linear increase of the crater depth with pulse number, we study the dependence of the ablation rate on the laser fluence by changing the target position relative to the focal plane. Fig. 2 depicts the dependence of the ablation rate on laser fluence, the graphs exhibiting two different regimes. In the first regime, increasing the laser fluence to a certain value (referred to as threshold fluence, $F_{t h}$ ) the ablation rate increases approximately logarithmically. The data in this domain are fitted by the equations

$\Delta h=\Delta h_{e} \cdot \ln \left(F / F_{\text {ath }}\right)$

where $F_{\text {ath }}$ is the ablation threshold fluence (e.g., the minimum laser fluence required for nonzero ablation rate) and $\Delta h_{e}$ is the ablation rate corresponding to the fluence $F=e \cdot F_{a t h}$. Thus, the fitting equations are

$\Delta h=1.0 \ln (F / 0.2)(\mu \mathrm{m})$

for $\mathrm{Al}$, 
$\Delta h=0.5 \ln (F / 4)(\mu \mathrm{m})$

for $\mathrm{Si}$, and

$\Delta h=0.2 \ln (F / 6.5)(\mu \mathrm{m})$

in the case of $\mathrm{LiNbO}_{3}$ target. Here, the fluence is given in $\mathrm{J} / \mathrm{cm}^{2}$.

Eqs. (3-5) indicate that the ablation threshold fluence of $\mathrm{Al}\left(\sim 0.2 \mathrm{~J} / \mathrm{cm}^{2}\right)$ is much smaller than in the case of silicon $\left(4 \mathrm{~J} / \mathrm{cm}^{2}\right)$ and $\mathrm{LiNbO}_{3}\left(6.5 \mathrm{~J} / \mathrm{cm}^{2}\right)$. This may be correlated with the optical absorption coefficient being larger for the metallic target than for the semiconductor and dielectric targets (table 1).

The comparison of the values of $\Delta h_{e}$ given in equations (3-5) and the corresponding laser fluences indicate a much higher efficiency of the ablation of $\mathrm{Al}$ as compared to silicon and lithium niobate. Further information on the efficiency of the three materials can be derived by comparing the ablation rate of the three materials at a given laser fluence. At 40 $\mathrm{J} / \mathrm{cm}^{2}$ fluence, the ablation rate of $\mathrm{Al}(\sim 5.5 \mu \mathrm{m} /$ pulse $)$ is $\sim 5$ times larger than $\mathrm{Si}(\sim 1.2$ $\mu \mathrm{m} /$ pulse $)$, and $\sim 11$ times larger than $\mathrm{LiNbO}_{3}(\sim 0.5 \mu \mathrm{m} /$ pulse $)$. The larger ablation rate obtained in the case of metallic target as compared to silicon and dielectric targets may be related to the large values of the optical absorption coefficient and thermal diffusivity of Al. Figure 3 gives a comparison of the ablation rates of the three materials as a function of optical and thermal parameters of the materials. The figure indicates that the ablation rate increases with the optical absorption coefficient (Fig. 3a), and thermal diffusivity (Fig. 3b).

In the second regime, increasing the laser fluence above the threshold value $F_{t h}$, the ablation rate has a sudden jump and increases further steeply (dash-dotted lines in Fig. 2). The threshold fluence is $\sim 70 \mathrm{~J} / \mathrm{cm}^{2}$ in the case of $\mathrm{Al}, \sim 90 \mathrm{~J} / \mathrm{cm}^{2}$ for $\mathrm{Si}$, and $\sim 180 \mathrm{~J} / \mathrm{cm}^{2}$ in the case of $\mathrm{LiNbO}_{3}$. Figure 4 presents the dependence of the threshold fluence on the optical absorption coefficient, indicating that the threshold fluence decreases with increasing the optical absorption coefficient of the material.

The jump in the ablation rate at the threshold fluence originates in the superposition of the phase explosion with the change in the plasma plume hydrodynamics. At the threshold fluence there is a transition from normal vaporisation to phase explosion at the critical temperature of the material. For all of the targets, the transition is indicated by the enhanced ejection and re-deposition of droplets around the craters [29]. The smaller value of the threshold fluence in the case of the metallic target as compared to the semiconductor and dielectric targets could be related to the large absorption coefficient of Al which facilitates reaching of the critical temperature during PLA, resulting in the large amount of melt that is observed at threshold around the craters as re-solidified droplets.

The dimensionality of the plasma hydrodynamics changes at the threshold fluence from one-dimensional to three-dimensional regime. The one-dimensional regime characterizes a high density and strong absorbent plasma plume which expands in axial direction, whereas the three-dimensional regime characterizes a less absorbent and low density plasma plume which expands both in axial and radial directions [3]. The jump in the ablation rate appears when the laser beam diameter (defined as the central Airy disk) becomes the same order of magnitude with the hydrodynamic length of the plasma plume. This relationship between the beam diameter and the hydrodynamic length of the plasma at threshold is demonstrated by a simple calculus as follows. The hydrodynamic length of the plasma is given by $[1,15]$

$l_{h}=\mathrm{v} \tau$

where $\tau$ is the pulse duration and $\mathrm{v}=\sqrt{\gamma k T / M}$ is the expansion velocity of the plasma plume considered as an ideal gas with adiabatic coefficient $\gamma=5 / 3$, temperature $T$, and atomic mass $M$, while $k$ is the Boltzmann constant. Considering a plasma temperature of $\sim 10^{5}$ 
$\mathrm{K}$ for $\mathrm{Al}[14,15], \sim 5 \cdot 10^{4} \mathrm{~K}$ for $\mathrm{Si}[30]$, and $\sim 10^{4} \mathrm{~K}$ for $\mathrm{LiNbO}_{3}$ [31] obtained when irradiating the targets with nanosecond pulses, eq. (6) gives a plasma hydrodynamic length of $\sim 50 \mu \mathrm{m}$. This length is similar with the diameter of the laser beam corresponding to the targets positions where the threshold fluence is reached.

\section{Conclusion}

We investigated the effects of pulse number and laser fluence on the ablation rate of metals $(\mathrm{Al})$, semiconductors $(\mathrm{Si})$, and dielectrics $\left(\mathrm{LiNbO}_{3}\right)$ by using nanosecond laser pulses at $532 \mathrm{~nm}$ wavelength in air at normal atmospheric conditions. The number of consecutive laser pulses hitting the target on the same area was varied from 5 to 40 , whereas the laser fluence was varied by changing the diameter of the irradiated area at the target surface. The dependence of the ablation rate on the pulse number indicate that the ablation rate is approximately constant during the first $\sim 15$ pulses, being $\sim 8.3 \mu \mathrm{m} /$ pulse for $\mathrm{Al}, \sim 2.7 \mu \mathrm{m} /$ pulse for $\mathrm{Si}$, and $\sim 1.7 \mu \mathrm{m} /$ pulse for $\mathrm{LiNbO}_{3}$ when placing the targets in the focal plane. Further increase of the pulse number lead to a decay of the ablation rate, the most significant $(\sim 50 \%)$ being in the case of dielectric target. The decrease of the ablation rate with pulse number was attributed to the superposition of two phenomena: the enhanced attenuation of the laser beam in the plasma plume which is confined within the crater, and the decay of the surface transmittance and of the effective laser fluence at the walls of the crater due to the gradual increase of the incidence angle of the laser beam at the irradiated area with pulse number. The much faster decrease of the ablation rate with pulse number obtained in the case of $\mathrm{LiNbO}_{3}$ as compared to the metallic and semiconductor targets was related to the small thermal diffusivity of $\mathrm{LiNbO}_{3}$.

The dependence of the ablation rate on the laser fluence indicates that the ablation rate of the three materials increases logarithmically with the fluence when the fluence is smaller than a threshold value. The threshold value depends on the target, being $\sim 70 \mathrm{~J} / \mathrm{cm}^{2}$ for $\mathrm{Al}, \sim 90$ $\mathrm{J} / \mathrm{cm}^{2}$ for $\mathrm{Si}$ and $\sim 180 \mathrm{~J} / \mathrm{cm}^{2}$ for $\mathrm{LiNbO}_{3}$. The relative efficiency of the ablation of the three materials was analysed here by comparing the ablation rate at a given laser fluence. The data indicate that, for a fixed value of laser fluence of $\sim 40 \mathrm{~J} / \mathrm{cm}^{2}$, the ablation rate is $\sim 5.5 \mu \mathrm{m} /$ pulse for $\mathrm{Al}, \sim 1.2 \mu \mathrm{m} /$ pulse for $\mathrm{Si}$, and $\sim 0.5 \mu \mathrm{m} /$ pulse for $\mathrm{LiNbO}_{3}$. The larger ablation rate obtained in the case of metallic target as compared to semiconductor and dielectric targets may be related to the large values of the optical absorption coefficient and thermal diffusivity of Al.

Increasing the fluence above the threshold value, lead to a sudden jump of the ablation rate followed by its steep increase. The jump of the ablation rate at the threshold fluence was attributed to the superposition of two effects: the transition from normal vaporisation to phase explosion regime at the critical temperature of the material, and the changes of dimensionality of the plasma hydrodynamics from one-dimensional to three-dimensional.

\section{REFERENCES}

1. D. Bauerle, Laser processing and chemistry, (Springer-Verlag, Berlin-Heidelberg-New York, 2000)

2. I.M. Popescu et. al., Aplicatii ale laserelor, (in Romanian, Ed. Tehnica, Bucuresti, 1979)

3. M. von Allemen, A. Bllatter, Laser-Beam Interaction with Materials, (Springer-Verlag, 1995)

4. D. Bauerle, Proceedings of an International Conference Laser Processing and Diagnostics, University of Linz, Springer-Verlag, Berlin-Heidelberg (1984) 
5. J. F. Ready, Effects of High-power Laser Radiation, (Academic Press, New York-London, 1971)

6. I. Ursu, I.N. Mihailescu, A.M. Prokhorov, V.I. Konov, Interactiunea radiatiei laser cu metalele, (in Romanian, Editura Academiei R.S.R., Bucuresti, 1986)

7. P. Simon, J. Ihlemann, Appl. Phys. A 63, 505 (1996)

8. J.C. Miller, R.F. Haglund (Eds.), Laser Ablation and Desorption, Experimental Methods in the Physical Sciences Vol. 30, (Academic Press, New York, 1998)

9. S.I. Anisimov, B.S. Lukyanchuk, Physics-Uspekhi 45, 293 (2002)

10. A. Vertes, R. Gijbels, F. Adams (Eds.), Laser ionization mass analysis, (John Wiley\&Sons, New York, 1993)

11. M. Stafe, I. Vladoiu, I.M. Popescu, Cent. Eur. J. Phys. 6, 327 (2008)

12. N.M. Bulgakova and A.V. Bulgakov, Appl. Phys. A 73, 199 (2001)

13. S. Amoruso, R. Bruzzese, N. Spinelli, R. Velotta, J. Phys. B 32, (1999)

14. S. Amoruso, M. Armenante, V. Berardi, R. Bruzzese, N. Spinelli, R. Velotta, Appl. Phys.

A 65, 265, (1997)

15. B.Wolff-Rottke, J. Ihlemann, H. Schmidt, Appl. Phys. A 60, 131, (1995)

16. A. Bogaerts, Z. Chen, Spectrochimica Acta B 60, 1280 (2005)

17. M. Stafe, C. Negutu, I.M. Popescu, Shock Waves 14, 123, (2005)

18. M. Stafe, C. Negutu, I.M. Popescu, Appl. Surf. Sci. 253, 6353 (2007)

19. B. Garrison, T. Itina, L. Zhigilei, Phys. Rev. E 68, 041501 (2003)

20. E.G. Gamaly, A.V. Rode, A. Perrone, A. Zocco, Appl. Phys. A 73, 143 (2001)

21. B.N. Chichkov, C. Momma, S. Nolte, F. von Alvensleben, A. Tunnermannet, Appl. Phys. A 63, 109 (1996)

22. A.E. Wynne, B.C. Stuart, Appl. Phys. A 76, 373 (2003)

23. S.M. Klimentov, S.V. Garnov, V.I. Konov, T.V. Kononenko, P.A. Pivovarov, O.G. Tsarkova, D. Breitling, F. Dausinger, Physics of Wave Phenomena 15, 1 (2007)

24. C. Porneala, D.A. Willis, Appl. Phys. Lett. 89, 211121 (2006)

25. J.M. Fishburn, M.J. Withford, D.W. Coutts, J.A. Piper, Appl. Opt. 43, 6473 (2004)

26. M.H.R. Knowles, G. Rutterford, D. Karnakis, A. Ferguson, The International Journal of Advanced Manufacturing Technology 33, 95 (2007)

27. A. Semerok, C. Chaleard, V. Detalle, J.L. Lacour, P. Mauchien, P. Meynadier, C. Nouvellon, B. Salle, P. Palianov, M. Perdrix, G. Petite, Appl. Surf. Sci. 138-139, 311 (1999)

28. CRC Handbook of Chemistry and Physics, 82nd edition, (Lide, D. R., Ed. CRC Press, Boca Raton, FL, 2001)

29. Q. Lu, Phys. Rev. E 67, 016410 (2003)

30. J.S. Cowpe, J.S. Astina, R.D. Pilkingtona, A.E. Hilla, Spectrochimica Acta Part B: Atomic Spectroscopy 63, 1066 (2008)

31. F. J. Gordillo-Vazquez, A. Perea, J. A. Chaos, J. Gonzalo, C. N. Afonso, Appl. Phys. Lett.

78, 7 (2001) 


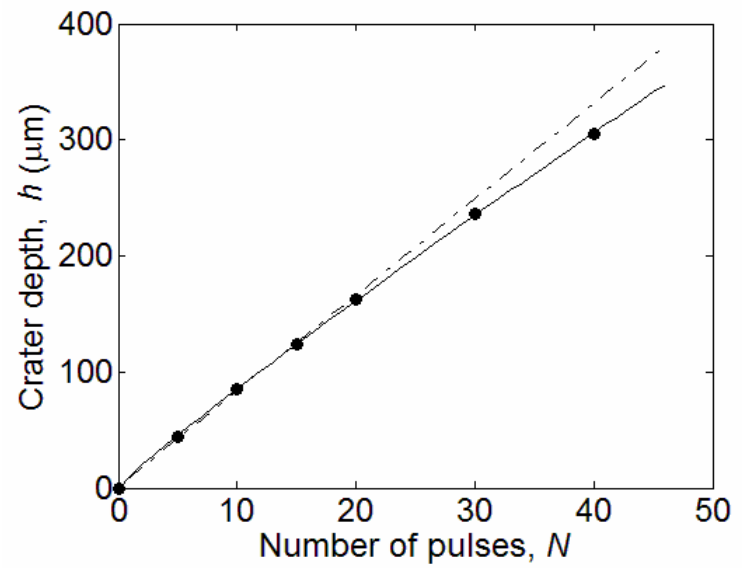

(a)

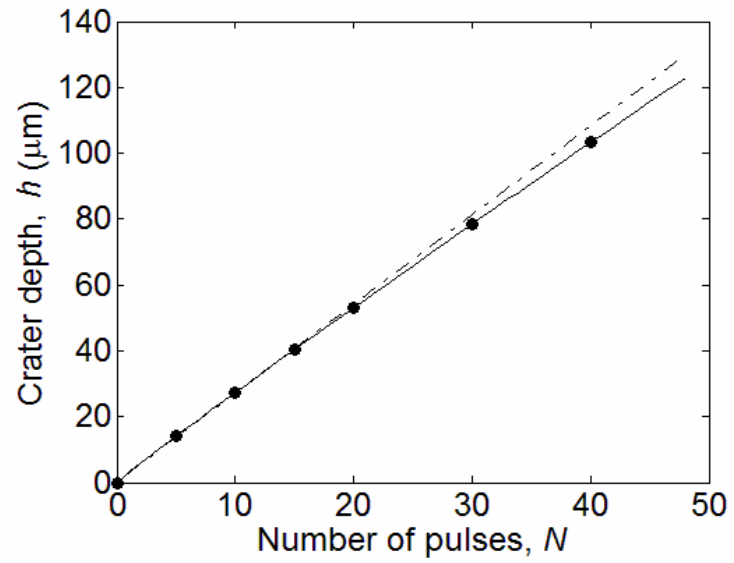

(b)

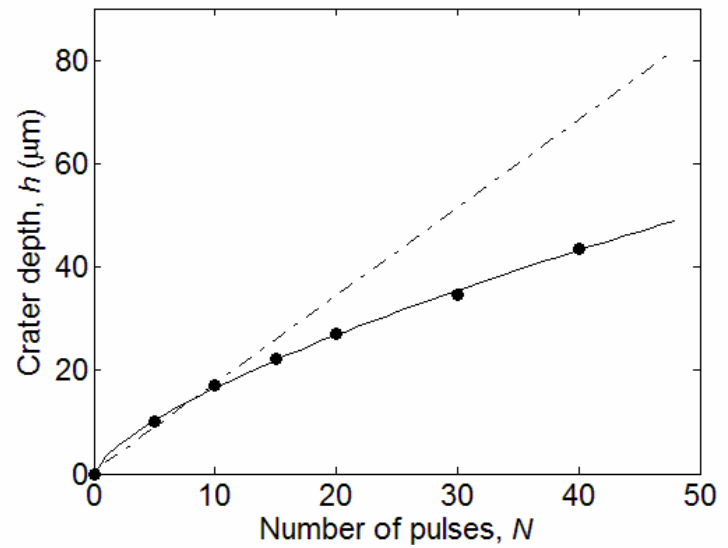

(c)

Figure 1. Crater depth as a function of pulse number for: (a) $\mathrm{Al}$, (b) $\mathrm{Si}$, and (c) $\mathrm{LiNbO}_{3}$. The solid lines represent the fitting curves described by eq. (1), and the dash-dotted lines represent the fitting curves for the linear regime which holds when pulse number is smaller than $\sim 15$ for $\mathrm{Al}$ and $\mathrm{Si}$, and $\sim 10$ for $\mathrm{LiNbO}_{3}$. 


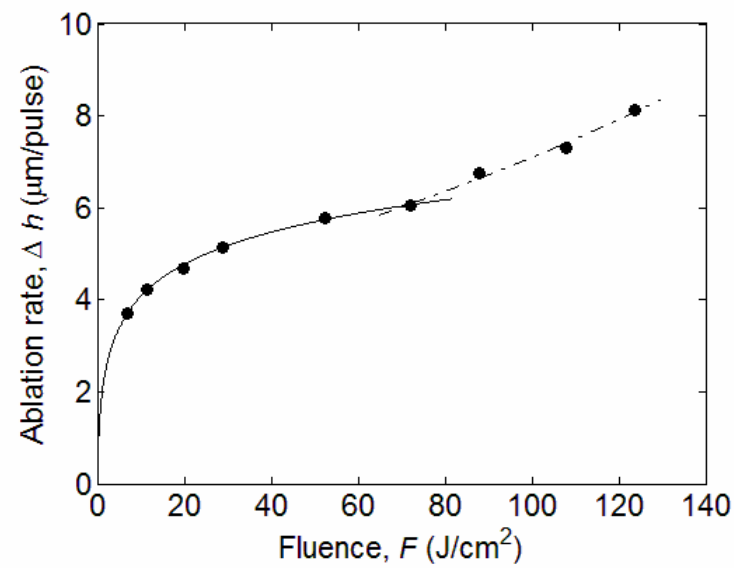

(a)

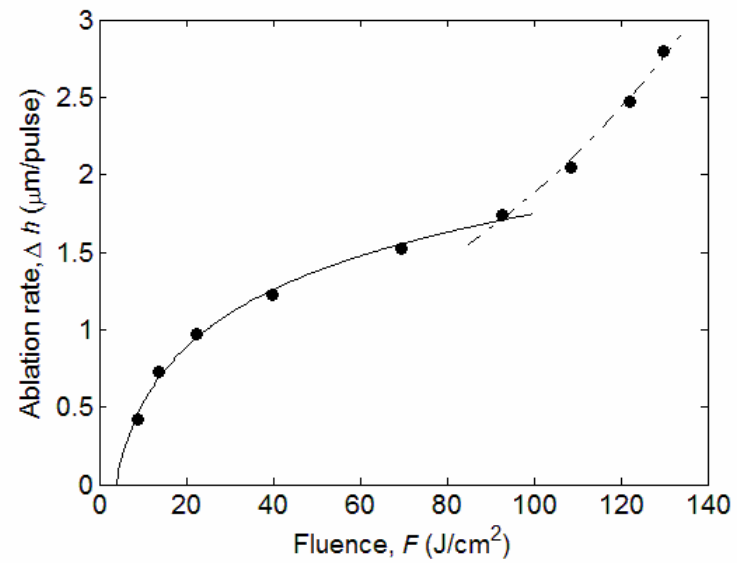

(b)

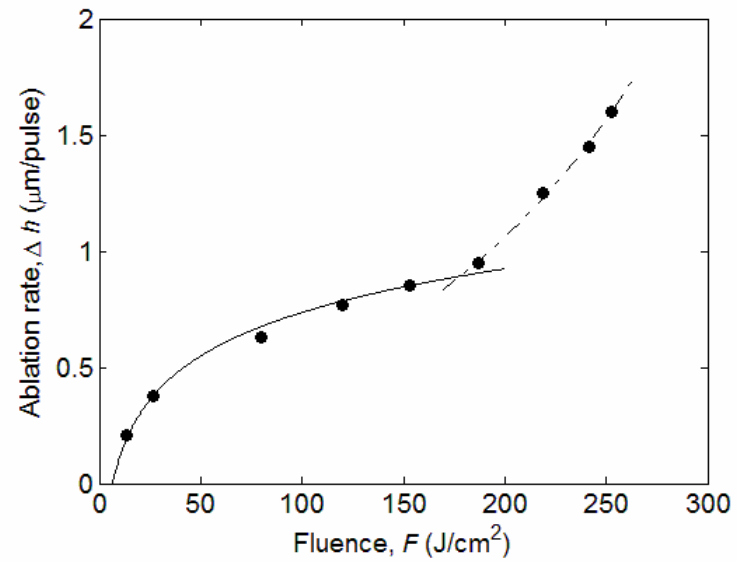

(c)

Figure 2. Ablation rate vs. laser fluence for: (a) $\mathrm{Al}$, (b) $\mathrm{Si}$, and (c) $\mathrm{LiNbO}_{3}$. The solid lines represent the fitting curves for the logarithmic regime, and the dash-dotted lines represent the fitting curves for the steep regime (above the threshold fluence) 


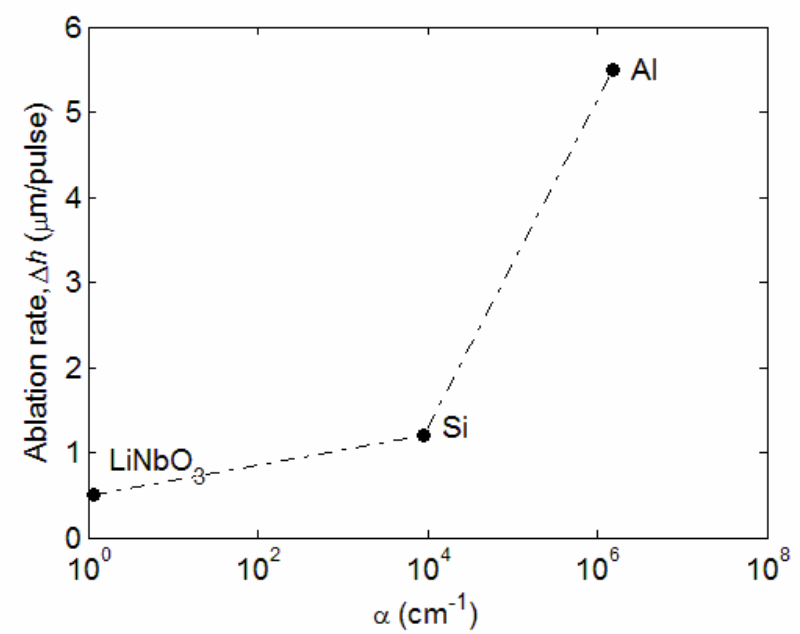

(a)

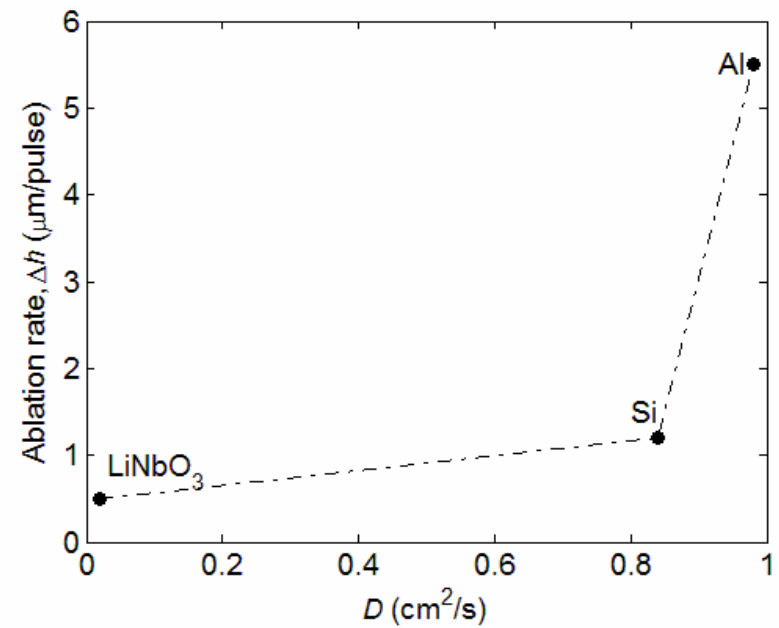

(b)

Figure 3. Ablation rate vs. optical absorption coefficient (a), and ablation rate vs. thermal diffusivity (b) at a fluence of $40 \mathrm{~J} / \mathrm{cm}^{2}$. The dash-dotted lines are depicted for guiding the eyes. 


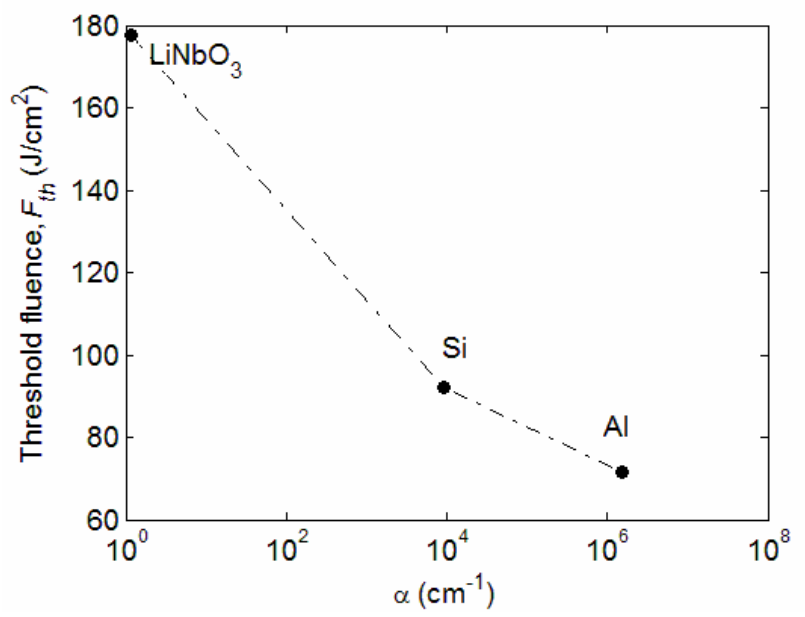

Fig. 4 Threshold fluence as a function of optical absorption coefficient of the materials. The dash-dotted lines are depicted for guiding the eyes.

Table I: Optical absorption coefficient, $\alpha$ (at $532 \mathrm{~nm}$ wavelength), and thermal diffusivity, $D$, of the targets

\begin{tabular}{|c|c|c|}
\hline Material & $\begin{array}{c}\alpha \\
\left(\mathrm{cm}^{-1}\right)\end{array}$ & $\begin{array}{c}D \\
\left(\mathrm{~cm}^{2} / \mathrm{s}\right)\end{array}$ \\
\hline $\mathrm{Al}$ & $1.5 \times 10^{6}$ & 0.98 \\
\hline $\mathrm{Si}$ & $0.9 \times 10^{4}$ & 0.84 \\
\hline $\mathrm{LiNbO}_{3}$ & $<1$ & 0.02 \\
\hline
\end{tabular}

